\title{
Aplicação de ferramentas SWOT e 5W2H para análise de consórcios intermunicipais de resíduos sólidos urbanos
}

\author{
Application of SWOT and 5W2H tools for analysis of solid \\ urban waste intermunicipal consortia
}

\section{Katia Sakihama Ventura Ana Beatriz Valim Suquisaqui}

\section{Resumo}

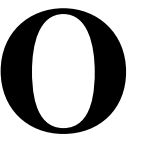

s municípios, especialmente de pequeno e médio porte, não possuem recursos financeiros e corpo técnico suficientes para a gestão eficiente e sustentável dos resíduos sólidos. A Política Nacional de Resíduos Sólidos, regulamentada pela Lei Federal 12.305/2010, aponta o consórcio público como um dos instrumentos para universalizar os serviços nesse setor. No entanto, há poucas pesquisas que abordam as dificuldades operacionais e as oportunidades existentes com este arranjo institucional. O objetivo do presente artigo foi analisar as potencialidades e os desafios da implementação de consórcios intermunicipais para a gestão de resíduos sólidos urbanos. A metodologia consistiu em levantamento bibliográfico sobre o tema, visita técnica a três consórcios públicos, análise documental e uso das ferramentas de gestão da qualidade SWOT e 5W2H. A principal dificuldade encontrada foi o comprometimento insuficiente de administradores públicos para tornar participativa a gestão de consórcio. Por outro lado, a coletividade se beneficia quando os consórcios promovem ações integradas, articulação intermunicipal, ganho financeiro e melhoria da capacidade técnica.

Palavras-chave: Consórcio público. Saneamento. Gestão ambiental. Sustentabilidade.

\begin{abstract}
Municipalities, especially small and medium-sized ones, lack the financial resources and technical staff necessary for the efficient and sustainable management of solid waste. The National Policy for Solid Waste, regulated by Federal Law 12.305/2010, recommend public consortia as a tool to universalise services in this sector. However, not many research studies have been done on the operational difficulties and opportunities provided by this type of institutional arrangement. The aim of this article is to analyse the potentials and challenges posed by the implementation of inter-municipal consortia for the management of solid urban waste. The methodology consisted of a bibliographic survey on the subject, technical visits to three public consortia, documentary analysis, and use of quality management tools (SWOT and $5 \mathrm{~W} 2 \mathrm{H}$ ). The main challenge encountered by the researchers was the public administrators' lack of commitment to the participatory management of the consortia. On the other hand, the community as a whole benefits when consortia succeed in promoting integrated actions, intermunicipal articulations, financial gains and improved technical capacity.

Keywords: Public consortium. Sanitation. Environmental management. Sustainability.
\end{abstract}

${ }^{1}$ Katia Sakihama Ventura ${ }^{1}$ Universidade Federal de São Carlos São Carlos - SP - Brasil

${ }^{2}$ Ana Beatriz Valim Suquisaqui ${ }^{2}$ Universidade Federal de São Carlos São Carlos - SP - Brasil

Recebido em 14/12/18

Aceito em 07/05/19 


\section{Introdução}

A geração de resíduos sólidos tem aumentado ao longo dos últimos anos no Brasil, superando o crescimento populacional no país, ao mesmo tempo em que ocorre a inflexão do produto interno bruto (PIB), como observado por Campos (2012). Tem havido também mais diversidade nas características dos produtos, mudança no padrão de consumo e descarte de resíduos sólidos pela obsolescência de uso, como citado por Garcia et al. (2016). Circunstâncias como estas têm ocasionado maior preocupação das entidades governamentais e mais atuação socioambiental (ORGANIZAÇÃO..., 2015).

Além disso, a alteração do padrão de consumo e a busca pela sustentabilidade nas cidades trazem outros elementos desafiadores à gestão de resíduos sólidos urbanos (RSU), tais como a minimização da geração de resíduos sólidos, o aproveitamento energético desse tipo de material, a inserção de tecnologias sustentáveis e a redução de conflitos socioambientais (MALHEIROS; PHILIPPI JUNIOR; COUTINHO, 2008).

Outra questão latente ao tema é o descarte inadequado de resíduos sólidos na área urbana. No Brasil, há cerca de 3.000 lixões em aproximadamente 1.600 municípios brasileiros, segundo Brasil (2019).

Os municípios de pequeno e médio porte são os que demandam maior atenção em virtude do aumento do déficit da prestação de serviço de coleta de resíduos nos últimos anos (BRASIL, 2019). Segundo Matos e Dias (2011), esses municípios são os mais desprovidos de recursos financeiros e têm falta de pessoal técnico qualificado para realizar a gestão de RSU.

Além disso, a escassez de áreas para implantação de aterros sanitários tem elevado os custos para destino adequado de RSU devido à busca de áreas apropriadas, que, na maioria das vezes, localizam-se mais distantes dos centros urbanos (PHILLIPI JUNIOR; AGUIAR, 2005).

Essas dificuldades operacionais podem ser minimizadas com a gestão compartilhada, a qual foi inserida pela Constituição Federal de 1988 ao estabelecer consórcios públicos e convênios de cooperação como mecanismos para resolver o problema dos RSU (BRASIL, 1988). Em 2005, com o advento da Lei federal 11.107, o consórcio público se tornou uma das alternativas para descentralizar a prestação de serviços em saneamento (BRASIL, 2005, 2007).

Em 2010, o setor de resíduos sólidos teve destaque no cenário nacional com a promulgação da Lei federal 12.305, que instituiu a Política Nacional de Resíduos Sólidos com vistas à gestão compartilhada de materiais e soluções consorciadas entre entes da federação. Diferentemente do Brasil, experiências internacionais sobre consórcios encontradas em literatura são, em sua maioria, de caráter privado. Alguns casos são apresentados a seguir.

Desde 1993, o consórcio italiano Consorzio Nazionale Imballaggi (Conai) (CONSORZIO..., 2017) foi constituído para valorizar a reciclagem de embalagens (COMISSÃO..., 2017).

Em outro estudo, observou-se que os serviços de coleta, tratamento e descarte de resíduos sólidos foram privatizados em cidades do sudeste asiático (NGOC; SCHNITZER, 2009). Os materiais foram destinados ao aterro sanitário, cujo local pertence ao poder público e é gerenciado por consórcio privado.

Na Malásia, a falta de recursos financeiros e humanos resultou na privatização do setor de resíduos sólidos (SAKAWI, 2011) e na constituição de quatro consórcios, a partir de 1993 (PERIATHAMBY; HAMID; KHIDZIR, 2009).

Outro exemplo de consórcio privado é o Southern Universities Waste Management Consortium (SUWMC), fruto da união de sete universidades do sul da Inglaterra e constituído para gerir os materiais dessas instituições (ZHANG et al., 2011).

Na esfera nacional, o governo brasileiro reconhece as deficiências dos serviços públicos de saneamento e resíduos sólidos. Por isso, incentiva a elaboração de planos municipais como acesso de recursos para a realização de obras e a prestação de serviços no setor (CONFEDERAÇÃO..., 2017).

Nesse aspecto, a administração pública municipal pode adotar medidas para a melhoria do desempenho da gestão de RSU tendo como base o uso de indicadores e ferramentas de controle de gestão. Esse conjunto de iniciativas otimiza os recursos financeiros investidos em áreas previstas pela política ambiental do município, auxilia a aplicabilidade de instrumentos legais e integra outros requisitos de natureza ambiental necessários ao processo de gestão de RSU (GAVIRA; MORAES; DADARIO, 2017). 
Contudo, as oportunidades e os conflitos advindos da constituição de consórcios intermunicipais são pouco conhecidos e necessitam de discussão aprofundada. Para isso, ferramentas de gestão auxiliam a análise, as quais são adotadas neste estudo.

No âmbito da gestão ambiental, Regra (2013) ressalta que as ferramentas de gestão podem minimizar certas fragilidades do processo, entre elas falta de estrutura, recursos financeiros insuficientes, falta de capacitação dos recursos humanos e falta de participação popular nos processos de tomada de decisão. Por serem instrumentos de fácil aplicação, permitem a realização de tarefas específicas e, consequentemente, a promoção de melhorias (HONDA, 2017).

O principal objetivo deste artigo foi analisar consórcios públicos intermunicipais para a gestão de resíduos sólidos urbanos mediante a avaliação das limitações e das dificuldades desse tipo de arranjo institucional. A maior contribuição científica resultante deste artigo foi a proposição de medidas para minimizar os desafios observados e, assim, subsidiar a tomada de decisão da administração pública sobre o assunto.

\section{Referencial teórico}

\section{Consórcios públicos e a gestão de resíduos sólidos urbanos}

A Política Nacional de Resíduos Sólidos (PNRS) tornou-se o marco legal no setor. Esse instrumento visa incentivar a formação de consórcios públicos para uma gestão regionalizada e integrada, ampliar a capacidade de gestão e proporcionar a redução de custos ao compartilhar os serviços de coleta, tratamento e destinação de resíduos sólidos (JACOBI; BESEN, 2011).

Os instrumentos legais que tratam do assunto, como a Constituição Federal e a PNRS, reportam a responsabilidade da prestação de serviço ao "titular dos serviços de limpeza urbana e de manejo de resíduos sólidos” (BRASIL, 2010). O consórcio é visto como um dos instrumentos para a obtenção de eficiência e de sustentabilidade econômica (RIBEIRO; RAZUK, 2014).

Os resíduos sólidos urbanos (RSU), quanto à origem, compreendem os resíduos domiciliares e aqueles provenientes da limpeza urbana, como definidos em Brasil (2010).

Um dos problemas da gestão de RSU é a falta de locais apropriados para dispô-los em cidades densamente urbanizadas (JACOBI; BESEN, 2011). Porém, outros aspectos interferem negativamente no processo, como a ineficiência dos serviços, o descarte inadequado, o mau gerenciamento de resíduos perigosos e de serviços de saúde e a falta de planejamento e recursos (SILVA; IMBROSI; NOGUEIRA, 2017). Nascimento Neto e Moreira (2012) e o IPEA (INSTITUTO..., 2012) destacam que os consórcios públicos têm a oportunidade de minorar essas adversidades.

Jacobi e Besen (2011) observaram que a sustentabilidade financeira dos serviços de limpeza urbana é uma questão que necessita de critérios mais específicos. Identificaram que mais de $50 \%$ dos municípios brasileiros não cobram por isso e, quando cobram, os valores são insuficientes para cobrir as despesas. O termo "sustentabilidade", neste artigo, se refere à capacidade do processo, do serviço ou da atividade de atender à demanda atual da população sem comprometer as necessidades das gerações futuras (COMISSÃO..., 1991).

Segundo Dias, Zavaglia e Cassar (2003, p. 243), “as empresas que adotam a gestão empresarial de sustentabilidade sempre esperam que seus produtos sejam escolhidos pelo consumidor por critérios que estejam além do preço", isto é, o consórcio que também provê sustentabilidade seleciona serviços que preservam o meio, com processos mais justos e eficientes.

A gestão em organizações privadas incorporou essas particularidades com a valorização de parâmetros ambientais (ALIGLERI, 2011), e, assim, os novos modelos de avaliação de processo favorecem a produção sustentável e garantem a competividade no ramo da indústria e dos serviços (DIAS; ZAVAGLIA; CASSAR, 2003).

Conforme Ferreira e Jucá (2017), a atuação de consórcios públicos sob a ótica da sustentabilidade se baseia na redução da geração e da disposição final de RSU, e, sobretudo, fomenta o uso de aterros sanitários em escala otimizada, inclui catadores e promove ações de geração de trabalho e renda.

\section{Desafios e oportunidades na implementação de consórcios públicos}

No cenário nacional, entre os 5.570 municípios brasileiros, aproximadamente $90 \%$ deles possuem população menor que 50.000 habitantes (IBGE, 2015). No que tange à gestão de RSU, o estudo de Silveira e Philippi 
(2008) aponta que os consórcios públicos atendem particularmente municípios com até 20.000 habitantes (FERREIRA; JUCÁ, 2017).

A Pesquisa de Informações Básicas Municipais, realizada pelo Instituto Brasileiro de Geografia e Estatística (IBGE, 2015), contempla o tema “meio ambiente e saúde” em consórcios públicos, no qual se insere o saneamento. Nesse documento, os municípios com menos de 50.000 habitantes (66,3\% dos 5.570) foram agrupados como aqueles organizados em consórcios. Observou-se que desses 3.691 municípios, 3.571 (96,7\%) são intermunicipais, com destaque para as regiões Sudeste, Sul e Centro-Oeste (IBGE, 2015).

Entre as dificuldades de funcionamento dos consórcios públicos, destacam-se a falta de articulação política, a descontinuidade da gestão pública, a ausência de troca de experiências, a garantia de recurso financeiro para cumprir o plano de trabalho, a falta de participação da população durante e após o processo de implantação e, por fim, a divulgação insuficiente dos resultados obtidos pelo consorciamento (TEIXEIRA; VENTURA, 2018; VENTURA; TEIXEIRA; KOTSUBO, 2017; VENTURA; KUSSABA, 2015).

A questão política se apresenta como uma ameaça ao funcionamento de consórcios porque pode se tornar difusa ao longo do tempo, o que gera dificuldades na coordenação regional das atividades, segundo Cruz et al. (2001) e Caldas (2003). Em outras palavras, o planejamento torna-se específico e de curto prazo, baseado em acordos pontuais para dar maior visibilidade política, e se torna insustentável para a cooperação intermunicipal, a ponto de limitar a ação dos consórcios públicos e até de levá-los à extinção (MOISÉS, 2001).

Segundo Mantovani (2001), a participação da sociedade nos consórcios mantém o funcionamento deles, enquanto a falta de capacitação de pessoal pode desmotivar a equipe gestora e inviabilizar a atuação do consórcio como agente mobilizador na região.

Entre as vantagens promovidas pelos consórcios públicos foram observados os seguintes aspectos:

(a) redução de custos operacionais;

(b) obtenção de ganhos na compra/aluguel de equipamentos e materiais de consumo;

(c) compartilhamento de recursos, equipamentos, pessoal e prestação de serviços;

(d) articulação da cooperação local e regional;

(e) fortalecimento da implantação de ações conjuntas;

(f) visão integrada entre planejamento ambiental e demandas de infraestrutura urbana;

(g) fortalecimento do processo de descentralização com a gestão compartilhada; e

(h) superação de conflitos políticos (FUNDAÇÃO..., 2017; FERREIRA; JUCÁ, 2017; VENTURA; TEIXEIRA; KOTSUBO, 2017; CAIXA..., 2011; MATOS; DIAS, 2011; CRUZ et al., 2001).

A aproximação dos consórcios com entidades da sociedade civil possibilita a formação de rede interinstitucional de cooperação para interesses coletivos, o que envolve diversos atores sociais (SILVEIRA; PHILIPPI, 2008).

De acordo com Ribeiro e Razuk (2014), os custos de serviços comuns sofrem significativa redução com o aumento da quantidade de municípios consorciados, o que está diretamente relacionado à densidade populacional e à geração diária de resíduos sólidos por habitante.

\section{Consórcios públicos: caso internacionais e nacionais}

Os consórcios de resíduos sólidos consolidados em casos internacionais são gerenciados por empresas privadas, diferentemente do Brasil. Aqui os municípios se organizam especialmente pelo fim dos lixões, mas também são induzidos por outras circunstâncias, como falta de recursos financeiros, exigências legais, oportunidade de captação de recursos, necessidade de compartilhamento de materiais ou equipamentos, elaboração de planos integrados (TEIXEIRA; VENTURA, 2018; SILVA; IMBROSI; NOGUEIRA, 2017).

Com o apoio da Fundação Nacional de Saúde (Funasa), Teixeira e Ventura (2018) identificaram mais de 150 experiências no país, as quais abrangem aproximadamente 47 milhões de habitantes (Tabela 1). O setor de resíduos sólidos foi o que contemplou o maior número populacional (31,5 milhões) e o maior número de municípios consorciados (539), como ilustra a Tabela 1.

O número de consórcios públicos atuantes em resíduos sólidos (92) foi excessivamente superior que o das demais categorias, tendo representado 59\% dos casos analisados pelos autores da pesquisa (Tabela 2).

336 Ventura, K. S.; Suquisaqui, A. B. V. 
Tabela 1 - Organização de consórcios públicos por tipo/categoria (até dezembro de 2017)

\begin{tabular}{l|c|c}
\hline \multicolumn{1}{c|}{ Tipo/categoria* } & Número de municípios & Habitantes \\
\hline 1 - Saneamento e outros & 132 & 10.161 .369 \\
2 - Exclusivamente saneamento & 211 & 5.351 .217 \\
3 - Somente resíduos sólidos & 539 & 31.517 .985 \\
\hline Total & $\mathbf{8 8 2}$ & $\mathbf{4 7 . 0 3 0 . 5 7 1}$ \\
\hline
\end{tabular}

Fonte: Teixeira e Ventura (2018).

Nota: *de acordo com a publicação de Teixeira e Ventura (2018), o termo "saneamento" segue a definição dada pela Política Nacional de Saneamento Básico e engloba os quatro eixos do saneamento (abastecimento de água, esgotamento sanitário, manejo de resíduos sólidos e limpeza urbana, manejo de águas pluviais). A expressão "saneamento e outros" corresponde aos serviços de saneamento nestes eixos, além de outros temas agrupados por interesse do próprio consórcio (educação ambiental, sustentabilidade, iluminação pública, meio ambiente, turismo, reflorestamento, entre outros).

Tabela 2 - Identificação de consórcios públicos por macrorregião (até dezembro de 2017)

\begin{tabular}{l|c|c|c}
\hline \multirow{2}{*}{ Região do Brasil } & \multicolumn{3}{|c}{ Área de atuação } \\
\cline { 2 - 4 } & $\begin{array}{c}\text { Saneamento } \\
\text { e outros }\end{array}$ & $\begin{array}{c}\text { Exclusivamente } \\
\text { saneamento }\end{array}$ & $\begin{array}{c}\text { Somente } \\
\text { resíduos sólidos }\end{array}$ \\
\hline Sul & 04 & 04 & 20 \\
\hline Sudeste & 28 & 04 & 27 \\
\hline Centro-Oeste & 08 & 08 & NC* \\
\hline Nordeste & NC* & 02 & 01 \\
\hline Norte & 06 & NC* & 01 \\
\hline Subtotal & $\mathbf{4 6 ~ ( 2 9 , 5 \% )}$ & $\mathbf{1 8 ( 1 1 , 5 \% )}$ & $\mathbf{9 2 ~ ( 5 9 \% )}$ \\
\hline TOTAL & \multicolumn{3}{|c|}{$\mathbf{1 5 6 ( 1 0 0 \% )}$} \\
\hline
\end{tabular}

Fonte: Teixeira e Ventura (2018).

Nota: *nada consta.

Em outro estudo brasileiro, Silva, Imbrosi e Nogueira (2017) identificaram 77 consórcios de resíduos sólidos, sendo o maior número de casos registrado no Nordeste (38), enquanto havia 25 no Sudeste, 11 no Sul, 2 no Centro-Oeste e 1 no Norte.

\section{Ferramentas de Gestão de Qualidade: SWOT e 5W2H}

No âmbito da gestão de consórcios, ferramentas de gestão da qualidade podem auxiliar a interpretação de informações qualitativas. Segundo Saraiva et al. (2007), Rodrigues et al. (2015) e Massukado (2004), essas ferramentas permitem prever incertezas e imprevistos no processo desconhecidos pelo gestor, ao mesmo tempo em que auxiliam a coleta, a organização e a análise de dados.

A matriz SWOT (Strengths, Weaknesses, Opportunities, Threats), idealizada por Albert Humphrey entre os anos 1960 e 1970 (GÜREL; TAT, 2017), é a mais utilizada em empresas de diversos países, independentemente de seu nível de desenvolvimento e de seu porte comercial (QEHAJA; KUTLLOVCI; PULA, 2017). Nakagawa (2012) reforça que ainda é preciso definir procedimentos e medidas para solucionar ou minimizar os problemas e, assim, aproveitar as oportunidades.

Outro instrumento útil para a avaliação de consórcios públicos é a matriz 5W2H, que define um plano de ação para as atividades (prazos, responsabilidades, recursos humanos, infraestrutura, recursos financeiros e técnicos) (MACHADO, 2012; SILVEIRA; MARTELLI; OLIVEIRA, 2016; PEINADO; GRAEML, 2007; WERKEMA, 1995).

\section{Método}

A abordagem do estudo foi do tipo descritiva sem a interferência do pesquisador. Barros e Lehfeld (2007) afirmam que esse tipo de pesquisa pode gerar trabalhos inéditos, quando se pretende rever, interpretar e apontar considerações teóricas.

Para o desenvolvimento desta pesquisa, as hipóteses assumidas foram: 
(a) o Consórcio Público de Resíduos Sólidos Urbanos (CP-RSU) auxilia a gestão pública e viabiliza a ampliação dos serviços de saneamento nos municípios brasileiros, especialmente no campo dos resíduos sólidos;

(b) o CP-RSU representa uma das estratégias que otimizam o uso de recursos financeiros à medida que eleva o número de municípios consorciados; e

(c) para implementar e consolidar o CP-RSU, os maiores desafios são garantir a articulação política dos municípios consorciados e praticar o contínuo planejamento coletivo.

A $1^{\text {a }}$ etapa foi um levantamento teórico baseado nas pesquisas documental e bibliográfica para consulta de documentos impressos, digitalizados em plataforma on-line e disponibilizados em livros, periódicos, teses, dissertações e outros volumes de mesma natureza sobre o tema da pesquisa.

A $2^{\text {a }}$ etapa consistiu na análise de documentos sobre o tema, considerou a análise de documentos institucionais (protocolo de intenções e estatuto social) de consórcios públicos e estudos de caso registrados em pesquisa bibliográfica. Foram realizadas visitas a três consórcios. Cabe esclarecer que os trabalhos científicos de Yosino (2013), Kussaba (2014) e Oliveira (2016) permitiram a análise da gestão de 23 consórcios públicos (Quadro 1). O método considerou os fatores (positivos, negativos, internos e externos) referentes às atividades, produtos ou serviços (Quadro 2) para a elaboração da matriz SWOT.

Por fim, a $3^{\text {a }}$ etapa compreendeu a proposição de medidas para minimizar os principais desafios com o uso da matriz 5W2H (Quadro 3).

\section{Quadro 1 - Consórcios públicos analisados}

\begin{tabular}{|c|c|c|}
\hline $\begin{array}{l}\text { CIRSURES (SC) } \\
\text { Consórcio Intermunicipal de } \\
\text { Resíduos Sólidos Urbanos da } \\
\text { Região Sul (de Santa Catarina) }\end{array}$ & $\begin{array}{l}\text { CIGRES (AL) } \\
\text { Consórcio Intermunicipal de } \\
\text { Gestão Integrada de Resíduos } \\
\text { Sólidos }\end{array}$ & $\begin{array}{l}\text { CIMBAJU (SP) } \\
\text { Consórcio Intermunicipal dos } \\
\text { Municípios da Bacia do Juqueri }\end{array}$ \\
\hline $\begin{array}{l}\text { CISGA Consórcio Intermunicipal } \\
\text { de Desenvolvimento Sustentável da } \\
\text { Serra Gaúcha }\end{array}$ & $\begin{array}{l}\text { CONSIMARES (SP) } \\
\text { Consórcio Intermunicipal de } \\
\text { Manejo de Resíduos Sólidos } \\
\text { da Região Metropolitana de } \\
\text { Campinas }\end{array}$ & $\begin{array}{l}\text { Grande ABC } \\
\text { Consórcio Intermunicipal da } \\
\text { Grande ABC }\end{array}$ \\
\hline $\begin{array}{l}\text { CONSAB (SP) } \\
\text { Consórcio Intermunicipal na Área } \\
\text { de Saneamento Básico }\end{array}$ & $\begin{array}{l}\text { CISAM - Meio Oeste (SC) } \\
\text { Consórcio Intermunicipal de } \\
\text { Saneamento Ambiental }\end{array}$ & $\begin{array}{l}\text { Consórcio Pró-Sinos (RS) } \\
\text { Consórcio Público de Saneamento } \\
\text { Básico da Bacia Hidrográfica do } \\
\text { Rio dos Sinos }\end{array}$ \\
\hline $\begin{array}{l}\text { CINCO (SC) } \\
\text { Consórcio Integrado do Contestado }\end{array}$ & $\begin{array}{l}\text { CISBRA (SP) } \\
\text { Consórcio Intermunicipal de } \\
\text { Saneamento Básico da Região } \\
\text { dos Circuitos das Águas }\end{array}$ & $\begin{array}{l}\text { Consórcio Sul Fluminense II (RJ) } \\
\text { Consórcio Público de Gestão de } \\
\text { Resíduos Sólidos Sul Fluminense II }\end{array}$ \\
\hline $\begin{array}{l}\text { CIRC (RS) } \\
\text { Consórcio Intermunicipal da } \\
\text { Região Centro do Estado do Rio } \\
\text { Grande do Sul }\end{array}$ & $\begin{array}{l}\text { CISAB - Zona da Mata } \\
\text { (MG) } \\
\text { Consórcio Intermunicipal de } \\
\text { Saneamento Básico da Zona } \\
\text { da Mata de Minas Gerais } \\
\end{array}$ & $\begin{array}{l}\text { ECOTRES (MG) } \\
\text { Consórcio Público Intermunicipal } \\
\text { de Tratamento de Resíduos Sólidos }\end{array}$ \\
\hline $\begin{array}{l}\text { CIRMS (BA) } \\
\text { Consórcio Intermunicipal da } \\
\text { Região Metropolitana de Salvador }\end{array}$ & $\begin{array}{l}\text { CITRESU (RS) } \\
\text { Consórcio Intermunicipal de } \\
\text { Tratamento de Resíduos } \\
\text { Sólidos Urbanos }\end{array}$ & $\begin{array}{l}\text { CORESA SUL (PI) } \\
\text { Consórcio Regional de Saneamento } \\
\text { do Sul do Piauí }\end{array}$ \\
\hline $\begin{array}{l}\text { CIDEMA (SC) } \\
\text { Consórcio Intermunicipal de } \\
\text { Desenvolvimento Econômico, } \\
\text { Social e Meio Ambiente }\end{array}$ & $\begin{array}{l}\text { CIMVI (SC) } \\
\text { Consórcio Intermunicipal do } \\
\text { Médio Vale do Itajaí }\end{array}$ & $\begin{array}{l}\text { GRANPAL (RS) } \\
\text { Consórcio Público da Associação } \\
\text { dos Municípios da Região } \\
\text { Metropolitana de Porto Alegre }\end{array}$ \\
\hline $\begin{array}{l}\text { CIGRES (RS) } \\
\text { Consórcio Intermunicipal de } \\
\text { Gestão de Resíduos Sólidos }\end{array}$ & $\begin{array}{l}\text { (SC) } \\
\text { Consórcio Intermunicipal do } \\
\text { Quiriri }\end{array}$ & \\
\hline
\end{tabular}

Fonte: Yosino (2013), Kussaba (2015) e Oliveira (2016). 
Quadro 2 - Conceituação da matriz SWOT

\begin{tabular}{|c|c|c|}
\hline & Fatores Positivos & Fatores Negativos \\
\hline 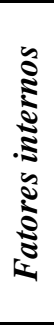 & $\begin{array}{l}\text { Strenghts (Força) } \\
\text { Situações ou aspectos que podem ser } \\
\text { internamente controláveis e exercem } \\
\text { influência positiva na execução de atividades } \\
\text { do município. } \\
\text { Exemplos: boas condições de infraestrutura, } \\
\text { pessoal qualificado, tecnologia acessível. }\end{array}$ & $\begin{array}{l}\text { Weaknesses (Fraquezas) } \\
\text { Situações ou aspectos controláveis que causam } \\
\text { desvantagem operacional ao poder público } \\
\text { municipal. Representam as fragilidades e as } \\
\text { vulnerabilidades do processo. } \\
\text { Exemplos: falta de recursos em geral, } \\
\text { desconhecimento de problemas operacionais e } \\
\text { gerenciais. }\end{array}$ \\
\hline 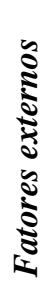 & $\begin{array}{l}\text { Opportunities (Oportunidades) } \\
\text { Situações ou aspectos incontroláveis, mas } \\
\text { que podem favorecer as atividades desde que } \\
\text { conhecidas. } \\
\text { Exemplos: dados populacionais, } \\
\text { instrumentos legais, usuários, participação } \\
\text { social, parcerias. }\end{array}$ & $\begin{array}{l}\text { Threats (Ameaças) } \\
\text { Situações ou aspectos incontroláveis que } \\
\text { dificultam as ações estratégicas, mas que podem } \\
\text { ser evitadas se forem conhecidas. } \\
\text { Exemplo: índices econômicos elevados, } \\
\text { competitividade, capacidade operacional, } \\
\text { custos. }\end{array}$ \\
\hline
\end{tabular}

Fonte: adaptado de Oliveira (2014), Morais (2008), Rezende (2008) e Chiavenato e Sapiro (2009).

\section{Quadro 3 - Exemplo de estruturação da matriz 5W2H}

\begin{tabular}{|l|l|}
\hline Fraqueza: Identificação do Problema \\
\hline What (O que será feito?) & Apresenta a atividade a ser realizada. \\
\hline Where (Onde?) & Estabelece o local da realização da atividade. \\
\hline Why (Por quê?) & Apresenta a justificativa da realização da atividade. \\
\hline Who (Quem?) & Aponta pessoas, setores e instituições envolvidas na atividade. \\
\hline When (Quando?) & Indica o período, a época ou o tempo de realização da atividade. \\
\hline How (Como?) & Indica o método e os procedimentos envolvidos na realização da atividade. \\
\hline How much (Quanto?) & Estima o custo da realização da atividade. \\
\hline
\end{tabular}

Fonte: adaptado de Silveira, Martelli e Oliveira (2016), Machado (2012) e Werkema (1995).

\section{Resultados e discussão}

\section{Análise dos desafios e oportunidades observados pela matriz SWOT}

As limitações e as possibilidades de consórcios públicos em resíduos sólidos encontram-se ilustradas no Quadro 4. O levantamento em literatura científica apresentou mais resultados positivos do que negativos nesse tema. Por outro lado, os desafios estão concentrados na consolidação dos consórcios públicos ao longo do tempo, devido à duração da gestão político-administrativa dos municípios (quatro anos).

A obtenção de recursos financeiros para os municípios integrantes de consórcios públicos de resíduos sólidos foi considerada como um aspecto prioritário (externo), devido ao artigo 42, inciso IV, da PNRS, que estabelece que os consórcios públicos legais têm prioridade na obtenção de recursos federais.

Entretanto, ao mesmo tempo em que esse fator representa uma vantagem significativa para muitos municípios, especialmente para os de menor porte, ele também se mostra como uma ameaça, uma vez que alguns municípios podem requerer esse tipo de formalização legal apenas com o intuito de atingir objetivos isolados com os recursos financeiros disponibilizados. O ganho financeiro com o apoio de financiamentos pode viabilizar e elevar a credibilidade dos consórcios existentes ou em fase de implantação. Outra questão considerada como ponto forte ao funcionamento interno e à atuação regional do consórcio público é a redução de custos operacionais, particularmente aqueles voltados para o destino adequado de resíduos sólidos.

Já o fortalecimento político entre os entes federados e o aumento de interação entre eles são os principais elementos político-administrativos dos consórcios, pois subsidiam o planejamento integrado e o propósito coletivo. Nesse contexto, considera-se vantagem que o consórcio público seja gerenciado por equipe ou empresa terceirizada, para que, mesmo com a troca da administração pública municipal, a gestão do consórcio tenha autossuficiência administrativa. 
Quadro 4 - Análise SWOT para funcionamento e consolidação de consórcio público intermunicipal de resíduos sólidos urbanos

\begin{tabular}{|c|c|c|c|}
\hline $\begin{array}{c}\text { Strenghts - Pontos fortes internos } \\
\text { (fortalezas) }\end{array}$ & Referências & $\begin{array}{l}\text { Weaknesses - Pontos } \\
\text { fracos internos } \\
\text { (fraquezas) }\end{array}$ & Referências \\
\hline $\begin{array}{l}1 \text { - Prioridade na obtenção de } \\
\text { financiamento federal }\end{array}$ & $\begin{array}{l}\text { Matos e Dias } \\
\quad(2011)\end{array}$ & \multirow{3}{*}{$\begin{array}{l}7 \text { - Dificuldade de } \\
\text { planejamento de } \\
\text { atividades no curto } \\
\text { prazo }\end{array}$} & \multirow{3}{*}{ Moisés (2001) } \\
\hline $\begin{array}{l}2 \text { - Planejamento integrado entre os } \\
\text { municípios }\end{array}$ & Moisés (2001) & & \\
\hline $\begin{array}{l}3 \text { - Otimização do uso de áreas para a } \\
\text { disposição dos resíduos sólidos } \\
\text { urbanos }\end{array}$ & Moisés (2001) & & \\
\hline 4 - Redução de custos operacionais & $\begin{array}{c}\text { Moisés (2001) } \\
\text { Ribeiro e } \\
\text { Razuk (2014) } \\
\text { Ventura, } \\
\text { Teixeira e } \\
\text { Kotsubo } \\
(2017) \\
\end{array}$ & $\begin{array}{l}8 \text { - Falta de } \\
\text { formalização entre } \\
\text { direitos e deveres de } \\
\text { cada ente consorciado }\end{array}$ & $\begin{array}{l}\text { Silveira e Philippi } \\
\text { (2008) }\end{array}$ \\
\hline $\begin{array}{l}5 \text { - Fortalecimento político entre os } \\
\text { entes federados e aumento da interação } \\
\text { entre estes }\end{array}$ & $\begin{array}{c}\text { Ribeiro e } \\
\text { Razuk (2014) }\end{array}$ & \multirow{2}{*}{$\begin{array}{l}9 \text { - Desequilíbrio de } \\
\text { poderes econômicos e } \\
\text { institucionais dos } \\
\text { municípios } \\
\text { consorciados }\end{array}$} & \multirow{2}{*}{$\begin{array}{l}\text { Nascimento Neto } \\
\text { e Moreira (2012) }\end{array}$} \\
\hline $\begin{array}{l}6 \text { - Utilização de aterros sanitários em } \\
\text { escala otimizada }\end{array}$ & $\begin{array}{c}\text { Ferreira e Jucá } \\
(2017)\end{array}$ & & \\
\hline $\begin{array}{l}\text { Opportunities - Pontos fortes } \\
\text { externos (oportunidades) }\end{array}$ & Referências & $\begin{array}{l}\text { Threats - Pontos } \\
\text { fracos externos } \\
\text { (ameaça) }\end{array}$ & Referências \\
\hline 10 - Instrumento de controle social & Moisés (2001) & $\begin{array}{l}18 \text { - Possibilidade de } \\
\text { interesses políticos } \\
\text { difusos e distintos da } \\
\text { vontade coletiva }\end{array}$ & $\begin{array}{l}\text { Cruz et al. (2001) } \\
\text { e Caldas (2003) }\end{array}$ \\
\hline $\begin{array}{l}11 \text { - Ganhos pelo aumento de escala de } \\
\text { serviço }\end{array}$ & $\begin{array}{l}\text { Moisés (2001) } \\
\text { Ventura, } \\
\text { Teixeira e } \\
\text { Kotsubo } \\
\text { (2017) } \\
\end{array}$ & $\begin{array}{l}19 \text { - Falta de } \\
\text { estabelecimento de } \\
\text { programa de educação } \\
\text { ambiental continuado }\end{array}$ & Mantovani (2001) \\
\hline $\begin{array}{l}12 \text { - Minimização de riscos e impactos } \\
\text { ambientais }\end{array}$ & Moisés (2001) & $\begin{array}{l}20 \text { - Ausência de } \\
\text { mecanismos para } \\
\text { garantir a participação } \\
\text { popular }\end{array}$ & $\begin{array}{l}\text { Nascimento Neto } \\
\text { e Moreira (2012) }\end{array}$ \\
\hline $\begin{array}{l}13 \text { - Favorecimento da adoção de } \\
\text { tecnologias avançadas }\end{array}$ & Moisés (2001) & \multirow{6}{*}{$\begin{array}{l}21 \text { - Fomento de } \\
\text { consórcios } \\
\text { intermunicipais que } \\
\text { não partilham } \\
\text { necessidades e anseios } \\
\text { comuns, mas somente } \\
\text { se estabelecem para } \\
\text { captar os recursos } \\
\text { federais disponíveis }\end{array}$} & $\begin{array}{l}\text { Nascimento Neto } \\
\text { e Moreira (2012) } \\
\end{array}$ \\
\hline $\begin{array}{l}14 \text { - Maior eficiência no uso de } \\
\text { recursos públicos }\end{array}$ & Vaz (1994) & & \\
\hline $\begin{array}{l}15 \text { - Aumento da transparência de } \\
\text { decisões públicas }\end{array}$ & Vaz (1994) & & \\
\hline $\begin{array}{l}16 \text { - Melhora na eficiência das funções } \\
\text { públicas }\end{array}$ & $\begin{array}{c}\text { Silveira e } \\
\text { Philippi (2008) }\end{array}$ & & \\
\hline $\begin{array}{l}17 \text { - Alternativa de integração regional } \\
\text { ascendente }\end{array}$ & Cruz (2001) & & \\
\hline $\begin{array}{l}17 \text { - Desenvolvimento de regiões } \\
\text { carentes }\end{array}$ & $\begin{array}{c}\text { Ribeiro e } \\
\text { Razuk (2014) }\end{array}$ & & \\
\hline
\end{tabular}

340 Ventura, K. S.; Suquisaqui, A. B. V. 
Outro benefício promovido pela implementação e atuação dos consórcios públicos é a articulação com organizações da sociedade civil. Isso favorece a conscientização e a mobilização da população às mudanças no padrão de consumo, bem como aproxima o papel do consórcio público ao desenvolvimento sustentável na gestão dos serviços públicos.

É possível estabelecer articulação político-regional junto à população com a existência do consórcio público. Com isso, intensificam-se mecanismos de participação popular e desperta-se o espírito coletivo na busca de soluções integradas e sustentáveis, com base nas premissas da PNRS e da Lei dos Consórcios.

Outra oportunidade considerada como prioritária foi a alternativa de integração regional ascendente, que significa ampliar a gestão consorciada com a integração de outros setores como os de recursos hídricos, de saneamento ambiental ou de planejamento do meio ambiente, com o desenvolvimento de política ambiental municipal descentralizada.

Com a estruturação da matriz SWOT foram identificados mais de 20 fatores (Quadro 4) que atuam diretamente na implementação e na consolidação de consórcios públicos de resíduos sólidos urbanos. Desse total sete foram compreendidos como obstáculos e, por isso, foram submetidos a análise com a ferramenta $5 \mathrm{~W} 2 \mathrm{H}$.

Como fraqueza tem-se a falta de formalização entre direitos e deveres de cada ente consorciado. Silveira e Philippi (2008) apontam que os direitos e deveres sejam estabelecidos em contrato para que não haja descumprimento legal das ações coletivas. Segundo esses autores, quando não há atendimento às metas determinadas no planejamento ou não são reorganizadas outras atividades, pode-se colocar em risco a manutenção do consórcio público e/ou trazer dificuldades operacionais futuras em todo o sistema de gestão dos resíduos.

Nesse contexto, outra ameaça aparente é a falta de programas de educação ambiental continuada. O desconhecimento da sociedade sobre o papel do consórcio pode comprometer o planejamento de atividades, os recursos obtidos, a infraestrutura necessária, o estabelecimento de parcerias e, principalmente, a continuidade do próprio consórcio. Para evitar isso, campanhas de mobilização socioambiental e de divulgação de informações em mídia digital são instrumentos de apoio ao cidadão que esclarecem os compromissos assumidos pelo consórcio na região.

\section{Elaboração de medidas para a eliminação ou a minimização dos desafios observados pela matriz 5W2H}

Todos os fatores internos e externos considerados negativos pelo SWOT foram analisados com a ferramenta 5W2H (Quadros 5 e 6). Os custos financeiros para análise desses fatores não foram contabilizados no presente estudo por se entender que cada atividade é proporcional ao tamanho populacional e à área de abrangência de cada município, bem como ao tempo e aos demais recursos (humanos, de infraestrutura, tecnológicos) que cada consórcio pode disponibilizar para as atividades descritas nos Quadros 5 e 6.

Cabe observar que os documentos identificados em literatura, os científicos com estudos de caso disponíveis em meio digital e as três visitas aos consórcios listados possibilitaram organizar as ações do Quadro 6.

Para que o consórcio público seja reconhecido e tenha apoio da sociedade na região é recomendável envolvê-la na maior parte das ações planejadas pelo consórcio, desde a intenção dos municípios se associarem até os motivos dessa união.

Ações de curto e médio prazo podem ser resolvidas de forma simples com a contratação de terceiros ou consultores especializados para elaborar o cronograma de atividades ao longo do tempo. A equipe gestora de consórcios públicos que atuar sem qualquer vínculo político-administrativo pode ter maior isonomia nas decisões do consórcio e probabilidade de permanecer na função por mais tempo.

Outro problema interno se refere à falta de formalização de direitos e deveres entre os entes federados. Esse problema pode ser resolvido por meio de documentação escrita de todas as decisões tomadas, para servir de base na elaboração do contrato de programa e contrato de rateio.

O último problema interno refere-se ao desequilíbrio de poderes econômicos e institucionais do município. Esse problema exige muita atenção dos gestores porque desencadeia dificuldades financeiras e, consequentemente, pode prejudicar os investimentos assumidos. É recomendável que se esclareçam os serviços contratados e pagos pelo consórcio com aporte financeiro dos entes consorciados, conforme o estabelecido nos contratos de rateio e de programa (número populacional, geração diária de resíduos sólidos urbanos, índices econômicos, entre outros). 
Quadro 5 - Aplicação da ferramenta 5W2H às fraquezas (pontos fracos internos) apontadas pela matriz SWOT

\begin{tabular}{|c|c|}
\hline \multicolumn{2}{|c|}{ Fraqueza 1: Dificuldade de planejamento de atividades no curto prazo } \\
\hline $\begin{array}{l}\text { O que será } \\
\text { feito? }\end{array}$ & $\begin{array}{l}\text { Propor a gestão do consórcio público por equipe terceirizada ou consultor especializado, } \\
\text { independente do vínculo político dos entes consorciados. } \\
\text { Estabelecer cronograma de atividades com o apoio de profissionais experientes em } \\
\text { planejamento estratégico para implementar ações no curto prazo, considerando os critérios } \\
\text { de i) facilidade operacional e gerencial; ii) baixo recurso financeiro e iii) apoio dos entes } \\
\text { consorciados na execução das atividades propostas. Em um segundo momento, as atividades } \\
\text { no médio e longo prazo podem ser elaboradas. }\end{array}$ \\
\hline Quando? & $\begin{array}{l}\text { Após a constituição legal do consórcio público ou a qualquer momento que o gestor solicitar } \\
\text { revisão do plano de ações. }\end{array}$ \\
\hline Quem? & $\begin{array}{l}\text { Gestor do CP-RSU, entes consorciados, sociedade civil (população em geral, lideranças } \\
\text { comunitárias, organizações não governamentais, instituições de ensino e pesquisa), } \\
\text { consultores. }\end{array}$ \\
\hline Onde? & $\begin{array}{l}\text { Sede física do consórcio (fixa ou alugada) ou em locais públicos com infraestrutura viável } \\
\text { (escolas, igrejas, entidades de classe, associações, outros). }\end{array}$ \\
\hline Por quê? & $\begin{array}{l}\text { Viabilizar o planejamento de atividades no curto prazo e reduzir incertezas da gestão } \\
\text { consorciada para posterior execução das atividades. }\end{array}$ \\
\hline Como? & $\begin{array}{l}\text { Estabelecer metas e indicadores de mensuração, orçar os investimentos necessários, } \\
\text { estabelecer de parceria do consórcio com outros interessados. }\end{array}$ \\
\hline \multicolumn{2}{|c|}{ Fraqueza 2: Falta de formalização entre direitos e deveres de entes consorciados } \\
\hline $\begin{array}{l}\text { O que será } \\
\text { feito? }\end{array}$ & $\begin{array}{l}\text { Estabelecer os direitos e deveres dos entes consorciados e documentar as decisões tomadas } \\
\text { para subsidiar a elaboração do contrato de programa e do contrato de rateio. }\end{array}$ \\
\hline Quando? & $\begin{array}{l}\text { A partir do momento em que se inicia o interesse pelo consorciamento, o gestor do CP-RSU } \\
\text { e os consultores jurídicos/contábeis elaboram a minuta do protocolo de intenções. } \\
\text { Após a finalização do protocolo de intenções, com a discussão dos ajustes, todos os } \\
\text { municípios assinam o contrato de programa e o transformam em protocolo de intenções } \\
\text { instituído. }\end{array}$ \\
\hline Quem? & Gestores municipais, gestor do CP-RSU. \\
\hline Onde? & Na sede das prefeituras interessadas. \\
\hline Por quê? & $\begin{array}{l}\text { Formalizar juridicamente o papel do CP-RSU e viabilizar a atuação dele entre os municípios } \\
\text { ou em escala regional. } \\
\text { Evitar discussões por falta de cumprimento dos acordos estabelecidos. }\end{array}$ \\
\hline Como? & $\begin{array}{l}\text { Realizar reuniões com os interessados pelo consorciamento para promover as intenções a } \\
\text { serem acordadas em contrato. }\end{array}$ \\
\hline \multicolumn{2}{|c|}{ Fraqueza 3: Desequilíbrio de poderes econômicos e institucionais dos municípios } \\
\hline $\begin{array}{l}\text { O que será } \\
\text { feito? }\end{array}$ & $\begin{array}{l}\text { Organizar os investimentos a serem feitos por cada município, considerando os serviços } \\
\text { consorciados e os parâmetros estabelecidos para o rateio (número populacional, geração de } \\
\text { resíduos sólidos urbanos, índices econômicos e legais do consórcio instituído, entre outros). }\end{array}$ \\
\hline Quando? & $\begin{array}{l}\text { Após o estabelecimento do CP-RSU, com o protocolo de intenções ratificado por todos } \\
\text { municípios. }\end{array}$ \\
\hline Quem? & Entes consorciados, assessores jurídicos/contábeis. \\
\hline Onde? & Sede física do consórcio (fixa ou alugada). \\
\hline Por quê? & $\begin{array}{l}\text { Garantir que o custo dos serviços seja adequado aos parâmetros estabelecidos no contrato de } \\
\text { programa e ao porte do município. }\end{array}$ \\
\hline Como? & $\begin{array}{l}\text { Ratear proporcionalmente os serviços consorciados aos municípios conforme parâmetros } \\
\text { estabelecidos no protocolo de intenções. }\end{array}$ \\
\hline
\end{tabular}


Quadro 6 - Ações propostas com a aplicação da ferramenta 5W2H às ameaças (pontos fracos externos) apontadas pela matriz SWOT (Continua...)

\begin{tabular}{|c|c|}
\hline \multicolumn{2}{|c|}{ Ameaça 1: Possibilidade de interesses políticos difusos e distintos da vontade coletiva } \\
\hline $\begin{array}{l}\text { O que será } \\
\text { feito? }\end{array}$ & $\begin{array}{l}\text { Promover discussões com a sociedade civil e com os municípios consorciados para } \\
\text { consolidar os interesses coletivos e atender aos anseios da população geral. }\end{array}$ \\
\hline Quando? & $\begin{array}{l}\text { Sempre que necessário, de forma planejada pelo gestor do CP-RSU ou a partir das } \\
\text { divergências intermunicipais. }\end{array}$ \\
\hline Quem? & $\begin{array}{l}\text { Gestor do CP-RSU, entes consorciados, sociedade civil (população em geral, lideranças } \\
\text { comunitárias, organizações não governamentais, instituições de ensino e pesquisa), } \\
\text { consultores. }\end{array}$ \\
\hline Onde? & $\begin{array}{l}\text { Sede física do consórcio (fixa ou alugada) ou em locais públicos com infraestrutura viável } \\
\text { (escolas, igrejas, entidades de classe, associações, outros). }\end{array}$ \\
\hline Por quê? & Garantir que os interesses coletivos prevaleçam e escala intermunicipal. \\
\hline Como? & $\begin{array}{l}\text { Realizar reuniões e seminários a todos os interessados. } \\
\text { Apresentar problemas específicos sobre resíduos sólidos urbanos e identificar aqueles que } \\
\text { podem ser integrados pelo CP-RSU. }\end{array}$ \\
\hline \multicolumn{2}{|c|}{ Ameaça 2: Falta de estabelecimento de programa de educação ambiental continuado } \\
\hline $\begin{array}{l}\text { O que será } \\
\text { feito? }\end{array}$ & $\begin{array}{l}\text { Instituir programas de educação ambiental para a população de forma continuada. } \\
\text { Planejar atividades de mobilização socioambiental ao longo do ano. }\end{array}$ \\
\hline Quando? & $\begin{array}{l}\text { No curto, médio e longo prazo. } \\
\text { Durante a existência do CP-RSU. } \\
\text { Sempre que houver necessidade (apoio à saúde pública, redução de impactos ambientais } \\
\text { pelas atividades humanas e gestão de riscos). }\end{array}$ \\
\hline Quem? & $\begin{array}{l}\text { Secretarias municipais de saúde, educação, meio ambiente e de obras/serviços públicos, } \\
\text { planejamento urbano, habitação. } \\
\text { Gestores públicos responsáveis pela gestão do saneamento e meio ambiente. } \\
\text { Entes consorciados. } \\
\text { Parceiros colaborativos (empresas de coleta de RSU, proprietários de caçambas, outros). }\end{array}$ \\
\hline Onde? & $\begin{array}{l}\text { Nos municípios consorciados, em locais com infraestrutura mínima para as ações planejadas } \\
\text { (igrejas, escolas, entidades de classe, organizações não governamentais, instituições de } \\
\text { pesquisa e ensino, entre outros). }\end{array}$ \\
\hline Por quê? & $\begin{array}{l}\text { Para sensibilizar a população da importância da constituição de um consórcio público e, } \\
\text { consequentemente, da gestão adequada de RSU, bem como de procedimentos apropriados } \\
\text { pelos munícipes (segregação de resíduos sólidos na fonte geradora) e da participação } \\
\text { voluntária em reuniões do CP-RSU. }\end{array}$ \\
\hline Como? & $\begin{array}{l}\text { Entregar materiais educativos (panfletos, mídias sociais, rádio, programa de televisão, carro } \\
\text { de som), realizar cursos e eventos, instituir mecanismos de aprimoramento da gestão de RSU } \\
\text { (ponto de entrega voluntária para materiais separados, terrenos limpos, outros). } \\
\text { Buscar financiamento para a educação ambiental nos comitês de bacia ou entidades } \\
\text { estaduais e na esfera federal. } \\
\text { Ampliar as campanhas de segregação de materiais, bem como incentivar a economia local e } \\
\text { o uso de materiais com maior durabilidade. }\end{array}$ \\
\hline
\end{tabular}


Quadro 6 - Ações propostas com a aplicação da ferramenta 5W2H às ameaças (pontos fracos externos) apontadas pela matriz SWOT (continuação)

\begin{tabular}{|c|c|}
\hline \multicolumn{2}{|c|}{ Ameaça 3: Ausência de mecanismos de participação popular } \\
\hline $\begin{array}{l}\text { O que será } \\
\text { feito? }\end{array}$ & $\begin{array}{l}\text { Criar canal de informação e participação popular em meio digital. } \\
\text { Realizar campanhas informativas sobre o consórcio público e os benefícios para a } \\
\text { sociedade. }\end{array}$ \\
\hline Quando? & $\begin{array}{l}\text { No curto, médio e longo prazo. Durante a existência do CP-RSU. Sempre que houver } \\
\text { necessidade (apoio à saúde pública, redução de impactos ambientais pelas atividades } \\
\text { humanas e gestão de riscos). }\end{array}$ \\
\hline Quem? & $\begin{array}{l}\text { Gestores públicos, gestor do consórcio, consultores jurídicos/contábeis, população em } \\
\text { geral, lideranças comunitárias, organizações não governamentais, instituições de ensino e } \\
\text { pesquisa, secretarias municipais de saúde, educação, meio ambiente e de obras/serviços } \\
\text { públicos, planejamento urbano, habitação. }\end{array}$ \\
\hline Onde? & $\begin{array}{l}\text { Os mecanismos podem ser por redes sociais, por e-mail (do consórcio público e das } \\
\text { prefeituras envolvidas) e em locais de fácil acesso à população (biblioteca, parque, praça, } \\
\text { escola, igreja, outros). }\end{array}$ \\
\hline Por quê? & $\begin{array}{l}\text { Beneficiar a própria população e possibilitar canais de participação em mídia digital e } \\
\text { acesso ao material impresso sobre o assunto a ser debatido/necessário aos munícipes, atuar } \\
\text { com transparência na sociedade e com os entes consorciados. }\end{array}$ \\
\hline Como? & $\begin{array}{l}\text { Criar conselhos gestores, realizar orçamento participativo, realizar encontros, inclusive com } \\
\text { transmissão ao vivo e com link disponibilizado para visualização posterior, disponibilizar } \\
\text { computadores com acesso à internet e telões em espaço público aberto à comunidade em } \\
\text { geral para apresentação das atividades, dos mecanismos, do papel do CP-RSU e das ações } \\
\text { consorciadas, entre outros, apresentar a problemática dos resíduos sólidos urbanos na região } \\
\text { em que foram compartilhados e mostrar que pode ser solucionada conjuntamente. }\end{array}$ \\
\hline \multicolumn{2}{|c|}{$\begin{array}{l}\text { Ameaça 4: Fomento de consórcios públicos intermunicipais que não partilham necessidades e } \\
\text { anseios comuns, mas somente se estabelecem para captar os recursos federais disponíveis }\end{array}$} \\
\hline $\begin{array}{l}\text { O que será } \\
\text { feito? }\end{array}$ & $\begin{array}{l}\text { Consolidar a ação conjunta dos municípios consorciados e apresentar periodicamente os } \\
\text { resultados e os compromissos assumidos por contratos de serviço. }\end{array}$ \\
\hline Quando? & $\begin{array}{l}\text { Quando houver fragilidade político-institucional detectada. No curto, médio e longo prazo. } \\
\text { Durante a existência do CP-RSU. Sempre que houver necessidade (apoio à saúde pública, } \\
\text { redução de impactos ambientais pelas atividades humanas e gestão de riscos). }\end{array}$ \\
\hline Quem? & $\begin{array}{l}\text { Consórcios bem-sucedidos, pesquisadores do assunto, cooperados carrinheiros informais, } \\
\text { empresas prestadoras de serviço por consórcio público, gestores públicos, gestor do } \\
\text { consórcio, consultores jurídicos/contábeis, população em geral, lideranças comunitárias, } \\
\text { organizações não governamentais, instituições de ensino e pesquisa, secretarias municipais } \\
\text { de saúde, educação, meio ambiente e de obras/serviços públicos, planejamento urbano, } \\
\text { habitação. }\end{array}$ \\
\hline Onde? & Nos municípios consorciados. \\
\hline Por quê? & $\begin{array}{l}\text { Evitar que municípios não cumpram com o planejado e, com isso, percam a credibilidade } \\
\text { de seu papel de atuação pela população. }\end{array}$ \\
\hline Como? & $\begin{array}{l}\text { Realizar reuniões e de seminários a todos os interessados, gravar depoimentos e situações } \\
\text { promissoras em vídeos, apresentar resultados dos serviços consorciados (fim dos lixões, } \\
\text { implantação e expansão da coleta seletiva, implementação da logística reversa, ampliação } \\
\text { do aterro sanitário, outros) e os municípios beneficiados, contratar equipe terceirizada com } \\
\text { experiência em consórcio público e sem aproximação política aos entes consorciados, } \\
\text { elaborar plano municipal de gestão integrada de resíduos sólidos (PMGIRS) para o } \\
\text { consórcio. }\end{array}$ \\
\hline
\end{tabular}

A descontinuidade política e a falta de articulação intermunicipal se relacionam de modo significativo e são desfavoráveis à consolidação da gestão consorciada, pois dependem da forma de gestão da administração pública ante os compromissos com o município que ela representa. Isso dificulta a proposta de ação única e isolada. Por isso, esses aspectos não foram contemplados nesta análise.

O Quadro 6 apresenta o plano de ação para as ameaças externas com o uso da ferramenta SWOT. 
A primeira ameaça externa está diretamente relacionada à possibilidade de interesses políticos difusos divergentes da vontade coletiva. Para isso, é útil que haja comunicação contínua do consórcio com a sociedade civil, tanto para contemplar as necessidades gerais e de bem comum, quanto para apresentar os resultados obtidos e estabelecer novas metas.

Outra ameaça é a falta de programas de educação ambiental continuada, o que pode ser resolvido com o envolvimento de parceiros, o planejamento de atividades ao longo do ano e a busca de financiamento para apoio a essas questões.

O terceiro problema externo se refere à falta de participação popular nas atividades do CP-RSU. Não há conhecimento, ao certo, sobre a forma de participação da população nos consórcios. Os debates e as discussões são algumas estratégias citadas pelo levantamento bibliográfico, porém não suficientes para garantir a efetividade dessa participação. Por isso, recomenda-se fortemente que outros canais de participação sejam desenvolvidos e amplamente divulgados a todos, como endereços eletrônicos integrados dos municípios consorciados e mídia digital e espaço aberto para levantamento de demandas por serviços básicos de resíduos sólidos urbanos. Nesse caso, não se pode esquecer de manter as informações atualizadas e equipe para pronto atendimento.

Por fim, o fomento de consórcios públicos intermunicipais com especial interesse em captar recursos disponíveis na esfera federal pode ser minimizado com a contratação de equipe terceirizada sem qualquer aproximação político-administrativa e por meio da apresentação periódica dos resultados obtidos pelo consórcio, com a lista dos municípios contemplados por atividade. Assim, pode-se garantir isonomia da distribuição de serviços.

O sucesso da implementação de consórcios públicos depende dos fatores comentados anteriormente, mas também de corpo técnico qualificado e independente da gestão pública (equipe terceirizada). Talvez, propor rodízio de sede física seja a forma mais justa de atender a todos os municípios consorciados. No entanto, devem ser considerados outros fatores (aluguel da nova edificação, transporte de mobiliário e, dependendo do contrato de pessoal, pagamento de diárias para deslocamento da equipe) para avaliar a viabilidade dessa iniciativa.

É recomendável o planejamento das ações consorciadas em consonância com o orçamento municipal para manter o compartilhamento de equipamentos (britadores de resíduos da construção civil, laboratório de análises de qualidade da água, caminhões de coleta diferenciada/reversa, entre outros) no consórcio. Por isso a importância da revisão do plano de ações, com novos objetivos e metas.

Com isso, a Lei dos Consórcios Públicos possibilitou a organização de uma nova personalidade jurídica, que representa todos os entes consorciados para organizar as despesas financeiras, administrativas e operacionais do consórcio público. Porém, o levantamento bibliográfico e documental permitiu observar que conflitos ainda permanecem, pois há consórcios públicos tidos como referência que, no presente momento, encontram-se extintos ou sem atualização de dados.

\section{Conclusão}

A constituição de arranjos intermunicipais para a gestão compartilhada de serviços técnicos em resíduos sólidos urbanos é uma das iniciativas apresentadas pela Política Nacional de Resíduos Sólidos.

A hipótese adotada no início da pesquisa foi confirmada, tendo sido identificado que a principal motivação foi a busca pelo fim dos lixões por força do próprio instrumento legal e também pela melhoria dos serviços de coleta e destino final.

O objetivo principal, analisar os desafios e as oportunidades da implementação de consórcios públicos em resíduos sólidos urbanos, foi atingido com o uso das ferramentas de qualidade SWOT e 5W2H.

A matriz SWOT identificou as limitações e as potencialidades da implementação e da consolidação de consórcios públicos, especialmente atuantes em resíduos sólidos. A visita técnica a alguns dos consórcios estudados foi essencial para a compreensão da vivência da instituição. Para a obtenção dos resultados, houve a necessidade de investimento de tempo maior que a expectativa inicial, justamente por falta de esclarecimentos das estratégias tomadas pelos consórcios e pela pouca divulgação dos resultados atingidos com a estruturação institucional.

A ferramenta 5W2H gerou proposições que podem auxiliar a consolidação de consórcios públicos ao longo do tempo. Isso está diretamente relacionado ao engajamento de diversos atores sociais, dos recursos financeiros disponíveis, do comprometimento entre as partes envolvidas, da intensa articulação entre os 
municípios, da visão coletiva e do papel desempenhado pelo gestor/equipe de gestores do consórcio, entre outros fatores supracitados.

A principal conclusão foi que os interesses político-administrativos podem tanto extinguir os consórcios públicos (se forem divergentes entre si) como enaltecer o papel deles (se forem comuns a todos), dependendo das intenções repassadas à equipe gestora.

\section{Referências}

ALIGLERI, L. M. Adoção de ferramentas de gestão para a sustentabilidade e a sua relação com os princípios ecológicos nas empresas. São Paulo, 2011. Tese (Doutorado em Administração) - Departamento de Administração da Faculdade de Economia, Administração e Contabilidade, Universidade de São Paulo, São Paulo, 2011.

BARROS, A. J. S.; LEHFELD, N. A. S. Fundamentos de metodologia científica. 3. ed. São Paulo: Pearson Prentice Hall, 2007.

BRASIL. Constituição. Constituição da República Federativa do Brasil. Brasília, 1988.

BRASIL. Lei ${ }^{\circ} 11.445$, de 5 de janeiro de 2007, que estabelece diretrizes nacionais para o saneamento básico. Diário Oficial da União, Brasília, 2007.

BRASIL. Lei n ${ }^{0} 11.107$, de 6 de abril de 2005, que dispõe sobre normas gerais de contratação de consórcios públicos e dá outras providências. Diário Oficial da União, Brasília, 2005.

BRASIL. Lei nº 12.305, de 2 de agosto de 2010, que institui a Política Nacional de Resíduos Sólidos. Diário Oficial da União, Brasília, 2010.

BRASIL. Ministério do Desenvolvimento Regional. Sistema Nacional de Informações sobre Saneamento: diagnóstico do manejo de resíduos sólidos urbanos - 2017. Brasília, 2019. Disponível em: http://www.snis.gov.br/diagnostico-residuos-solidos/diagnostico-rs-2017. Acesso em: 26 fev. 2019.

CAIXA ECONOMICA FEDERAL. Guia dos consórcios públicos: o papel dos prefeitos e das prefeitas na criação e na gestão dos consórcios públicos. Brasília, 2011. (Caderno 1). Disponível em:

http://www.caixa.gov.br/Downloads/consorcios-publicosguia/guia_consorcios_publicos_Vol1.pdf. Acesso em: 20 set. 2018.

CALDAS, E. L. CITRESU: Consórcio Intermunicipal de Tratamento de Resíduos Sólidos Urbanos. In: LOTTA, G. S. et al. (org.). 20 experiências de gestão pública e cidadania. São Paulo: Programa Gestão Pública e Cidadania; FGV, 2003.

CAMPOS, H. K. T. Renda e evolução da geração per capita de resíduos sólidos no Brasil. Engenharia Sanitária e Ambiental, v. 17, n. 2, p. 171-180, 2012.

CHIAVENATO, I.; SAPIRO, A. Planejamento estratégico: fundamentos e aplicações da intenção aos resultados. 2. ed. Rio de Janeiro: Elsevier Campus, 2009.

COMISSÃO MUNDIAL SOBRE MEIO AMBIENTE E DESENVOLVIMENTO. Nosso futuro comum. Rio de Janeiro: FGV, 1991.

CONFEDERAÇÃO NACIONAL DA INDÚSTRIA. Investimentos em saneamento com recursos do fundo de garantia do tempo de serviço (FGTS): uma agenda de simplificação e otimização. Brasília: CNI, 2017.

CONSORZIO NAZIONALE IMBALLAGGI. Packaging recovery in Italy: the Conai System. 2017. Disponível em: http://www.conai.org/wp-content/uploads/2014/09/The-CONAI-System_-2017.pdf. Acesso em: 15 set. 2019.

CRUZ, M. C. M. T. et al. Consórcios intermunicipais: uma alternativa de integração regional ascendente. São Paulo: Instituto Pólis, 2001.

DIAS, R.; ZAVAGLIA, T.; CASSAR, M. Introdução à administração: da competitividade à sustentabilidade. São Paulo: Alínea, 2003.

FERREIRA, C. F. A.; JUCÁ, J. F. T. Metodologia para avaliação dos consórcios de resíduos sólidos urbanos em Minas Gerais. Engenharia Sanitária Ambiental, v. 22, n. 3, p. 513-521, 2017. 
FUNDAÇÃO NACIONAL DE SAÚDE. Estruturação e implementação de consórcios públicos de saneamento. Brasília: Funasa, 2017.

GARCIA, M. B. S. et al. Resíduos sólidos: responsabilidade compartilhada. Revista Científica Semioses, v. 9, n. 2, p. 77-91, 2016.

GAVIRA, M. O.; MORAES, C. S. B.; DADARIO, A. M. V. Administração e gestão sustentável: contexto e ferramentas. São Carlos: Rima, 2017.

GUREL, E.; TAT, M. SWOT Analysis: a theoretical review. The Journal of International Social Research, v. 10, n. 51, p. 994-1006, 2017.

HONDA, A. B. Aplicação de ferramentas de gestão da qualidade em ambientes de serviços hospitalares: estudo de medidas de melhoria em Santa Casa de Misericórdia no interior do estado de São Paulo, 2017. Dissertação (Mestrado em Engenharia de Produção) - Escola de Engenharia de São Carlos, Universidade de São Paulo, São Carlos, 2017.

INSTITUTO BRASILEIRO DE GEOGRAFIA E ESTATÍSTICA. Perfil dos municípios brasileiros 2015. Disponível em: https://biblioteca.ibge.gov.br/index.php/biblioteca-catalogo?view=detalhes\&id=295942. Acesso em: 24 abr. 2018.

INSTITUTO DE PESQUISA ECONÔMICA APLICADA. Diagnóstico dos instrumentos econômicos e sistemas de informação para gestão de resíduos sólidos. Relatório de pesquisa. Brasília, 2012.

JACOBI, P. R.; BESEN, G. R. Solid waste management in São Paulo: the challenges of sustainability. Estudos Avançados, v. 25, n. 71, p. 135-158, 2011.

KUSSABA, C. T. Estudo de avaliação de consórcios intermunicipais de gestão de saneamento básico no Brasil. São Carlos, 2014. Trabalho de Conclusão de Curso (Graduação em Engenharia Civil) Departamento de Engenharia Civil, Universidade Federal de São Carlos, São Carlos, 2014.

MACHADO, S. S. Gestão da qualidade. Inhumas: IFG; Santa Maria: Universidade Federal de Santa Maria, 2012.

MALHEIROS, T. F.; PHILIPPI JUNIOR, A.; COUTINHO, S. M. V. Agenda 21 nacional e indicadores de desenvolvimento sustentável: contexto brasileiro. Saúde e Sociedade, v. 17, n. 1, p. 7-20, 2008.

MANTOVANI, M. C. Consórcio Intermunicipal: instrumento de ação e desenvolvimento de políticas públicas e participação social em meio ambiente. Informativo Cepam. Consórcio: uma forma de cooperação intermunicipal - Estudos, legislação básica e pareceres. São Paulo: Fundação Prefeito Faria Lima; Cepam; Unidade de Políticas Públicas, v. 1, n. 2, p. 105-122, 2001.

MASSUKADO, L. M. Sistema de apoio à decisão: avaliação de cenários de gestão integrada de resíduos sólidos urbanos domiciliares. São Carlos, 2004. Dissertação (Mestrado em Engenharia Urbana) - Programa de Pós-Graduação em Engenharia Urbana, Universidade Federal de São Carlos, São Carlos, 2004.

MATOS, F.; DIAS, R. A gestão de Resíduos Sólidos e a formação de Consórcios intermunicipais. Revista em Agronegócio e Meio Ambiente, v. 4, n. 3, p. 501-519, 2011.

MOISÉS, H. N. Cooperação intermunicipal para a gestão do lixo. Informativo Cepam 109. Consórcio: uma forma de cooperação intermunicipal. São Paulo: Fundação Prefeito Faria Lima, 2001.

MORAIS, M. A análise S.W.O.T aplicada às vendas hoje! 2008. Disponível em: http://www.artigonal.com/vendas-artigos/a-analise-swot-aplicada-as-vendas-hoje-352133.html. Acesso em: 10 nov. 2018.

NAKAGAWA, M. Ferramenta 5W2H: plano de ação para empreendedores. São Paulo: Globo, 2012.

NASCIMENTO NETO, P. N.; MOREIRA, T. A. Consórcio intermunicipal como instrumento de gestão de resíduos sólidos urbanos em regiões metropolitanas: reflexões teórico-conceituais. Revista Brasileira de Gestão e Desenvolvimento Regional, v. 8, n. 3, p. 239-282, 2012.

NGOC, U. N.; SCHNITZER, H. Sustainable solutions for solid waste management in Southeast Asian countries. Waste Management, v. 29, n. 6, p. 1982-1995, 2009.

OLIVEIRA, D. P. R. Planejamento estratégico: conceitos, metodologias e práticas. São Paulo: Atlas, 2014.

OLIVEIRA, J. B. Metodologia de avaliação de consórcios públicos brasileiros de resíduos sólidos ou saneamento com o uso de indicadores de sustentabilidade. São Carlos, 2016. Trabalho de Conclusão de 
Curso (Graduação em Engenharia Civil) - Departamento de Engenharia Civil, Universidade Federal de São Carlos, 2016.

ORGANIZAÇÃO DAS NAÇÕES UNIDAS. Transformando nosso mundo: a Agenda 2030 para o desenvolvimento sustentável. Nações Unidas, 2015. Disponível em: https://nacoesunidas.org/wpcontent/uploads/2015/10/agenda2030-pt-br.pdf. Acesso em: 2 fev. 2019.

PEINADO, J.; GRAEML, A. R. Administração da produção: operações industriais e de serviços. Curitiba: UnicenP, 2007.

PERIATHAMBY, A.; HAMID, F. S.; KHIDZIR, K. Evolution of solid waste management in Malaysia: impacts and implications of the solid waste bill. Journal of Material Cycles and Waste Management, v. 11, n. 2, p. 96-103, 2009.

PHILLIPI JUNIOR, A.; AGUIAR, A.O. Resíduos sólidos: características e gerenciamento. In: PHILIPPI JUNIOR, A. (org.). Saneamento, saúde e ambiente: fundamentos para um desenvolvimento sustentável. São Paulo: Manole, 2005.

QEHAJA, A. B.; KUTLLOVCI, E.; PULA, J. S. Strategic management tools and techniques usage: a qualitative review. Acta Universitatis Agriculturae et Silviculturae Mendelianae Brunensis, v. 65, n. 2, p. 585-600, 2017.

REGRA, A. P. M. Cenários como ferramenta na gestão ambiental municipal: um estudo de caso em Brotas - SP. São Carlos, 2013. Dissertação (Mestrado em Ciências da Engenharia Ambiental) - Escola de Engenharia de São Carlos, Universidade de São Paulo, São Carlos, 2013.

REZENDE, D. A. Planejamento estratégico para organizações: públicas e privadas. Rio de Janeiro: Brasport, 2008.

RIBEIRO, M. C. P.; RAZUK, N. P. C. Consórcio público e gerenciamento de resíduos sólidos: aspectos de eficiência e cooperação. Revista Pensar, v. 19, n. 1, p. 151-178, 2014.

RODRIGUES, G. C. et al. Utilização de ferramentas da qualidade em um plano de gerenciamento de resíduos da construção civil. In: SIMPÓSIO INTERNACIONAL DE GESTÃO DE PROJETOS, INOVAÇÃO E SUSTENTABILIDADE, 4., São Paulo, 2015. Anais [...] São Paulo, 2011.

SAKAWI, Z. Municipal solid waste management in Malaysia: solution for sustainable waste management. Journal of Applied Sciences in Environmental Sanitation, v. 6, n. 1, p. 29-38, 2011.

SARAIVA, G. D. I. et al. A metodologia de análise do ciclo de vida, apoiada pelo software Umberto, como ferramenta de gestão na perspectiva da sustentabilidade: um estudo de caso. In: SIMPÓSIO DE EXCELÊNCIA EM GESTÃO E TECNOLOGIA, 4., Foz do Iguaçu, 2007. Anais [...] Foz do Iguaçu, 2007.

SILVA, W. M. F.; IMBROSI, D.; NOGUEIRA, J. M. Municipal solid waste management: public consortia as an alternative sacale-efficient?: lessons from the Brazilian experience. Current Urban Studies, v. 5, p. 185-201, 2017.

SILVEIRA, H. E.; MARTELLI, R.; OLIVEIRA, V. V. A implantação da ferramenta 5W2H como auxiliar no controle da gestão da empresa agropecuária São José. Revista de Administração do Sul do Pará, v. 3, n. 2, p. 68-80, 2016.

SILVEIRA, R. C. E.; PHILIPPI, L. S. Consórcios públicos: uma alternativa viável para a gestão regionalizada de resíduos sólidos urbanos. Revista Redes, v. 13, n. 1, p. 205-224, 2008.

TEIXEIRA, B. A. N.; VENTURA, K. S. Metodologia para formulação de consórcios para gestão integrada em saneamento ambiental (relatório final). Brasília: Funasa, 2018.

VAZ, J. C. Avaliando a gestão. Dicas n. 24, 1994. Disponível em: http://www.polis.org.br/uploads/309/309.pdf. Acesso em: 31 ago. 2018.

VENTURA, K. S.; KUSSABA, C. Estudo da formação de consórcios públicos em saneamento. In: EXPOSIÇÃO DE EXPERIÊNCIAS MUNICIPAIS EM SANEAMENTO, 19., Poços de Caldas, 2015. Anais [...] Poços de Caldas, 2015.

VENTURA, K. S.; TEIXEIRA, B. A. N.; KOTSUBO, K. Análise de consórcios públicos de resíduos sólidos como subsídio à gestão do saneamento (III-290). In: CONGRESSO ASSOCIAÇÃO BRASILEIRA DE ENGENHARIA SANITÁRIA E AMBIENTAL/FENASAN, São Paulo, 2017. Anais [...] São Paulo, 2017. 
WERKEMA, M. C. C. Ferramentas estatísticas básicas para o gerenciamento de processos. Belo Horizonte: Fundação Christiano Ottoni, 1995.

YOSINO, C. O. Estudo de consórcios públicos intermunicipais de gestão de resíduos sólidos no Brasil. São Carlos, 2013. Trabalho de Conclusão de Curso (Graduação em Engenharia Civil) - Departamento de Engenharia Civil, Universidade Federal de São Carlos, São Carlos, 2013.

ZHANG, N. et al. Greening academia: developing sustainable waste management at higher education institutions. Waste Management, v. 31, n. 7, p. 1606-1616, 2011.

\section{Katia Sakihama Ventura}

Programa de Pós-Graduação em Engenharia Urbana | Universidade Federal de São Carlos | Rod. Washington Luiz, km 235 | São Carlos - SP - Brasil | CEP 13565-905 | Tel.: (16) 3351-9673| E-mail: katiaventura@yahoo.com

\section{Ana Beatriz Valim Suquisaqui}

Programa de Pós-Graduação em Engenharia Urbana | Universidade Federal de São Carlos | Tel.: (16) 99727-5340| E-mail: biasuqui@hotmail.com

\section{Ambiente Construído}

Revista da Associação Nacional de Tecnologia do Ambiente Construído

Av. Osvaldo Aranha, 99 - 3o andar, Centro

Porto Alegre - RS - Brasil

CEP 90035-190

Telefone: +55 (51) 3308-4084

Fax: +55 (51) 3308-4054

www. seer. ufrgs. br/ ambienteconstruido

E-mail: ambienteconstruido@ufrgs.br 